\title{
Fabrication and characterization of $\mathrm{Zn}$ doped $\mathrm{CuO}$ nanofiber using newly designed nanofiber generator for the photodegradation of methylene blue from textile effluent
}

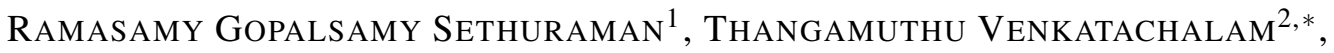 \\ SELVARAJ DINESH KIRUPHA ${ }^{3}$ \\ ${ }^{1}$ Department of Physics, Kumaraguru College of Technology, Coimbatore-641 049, India \\ ${ }^{2}$ Department of Physics, Coimbatore Institute of Technology, Coimbatore-641 014, India \\ ${ }^{3}$ Department of Chemistry, Coimbatore Institute of Technology, Coimbatore-641 014, India
}

\begin{abstract}
High aspect ratio, $\mathrm{Zn}$ doped copper oxide $(\mathrm{Zn}-\mathrm{CuO})$ nanofibers have been fabricated employing a newly designed electrospun coating unit using copper acetate, sodium hydroxide and polyethylene glycol in aqueous state. The prepared $\mathrm{Zn}$ doped copper oxide $(\mathrm{Zn}-\mathrm{CuO})$ nanofibers were sintered at $400{ }^{\circ} \mathrm{C}, 500{ }^{\circ} \mathrm{C}$ and $600{ }^{\circ} \mathrm{C}$ separately and characterized using X-ray diffraction XRD, Fourier transformation infrared spectroscopy FT-IR, scanning electron microscopy SEM, energy dispersive spectroscopy EDS. The average crystallite size was in the range of $28 \mathrm{~nm}$ to $30 \mathrm{~nm}$. Optical properties of $\mathrm{Zn}-\mathrm{CuO}$ nanofibers were analyzed using UV-DRS studies which showed a blue shift in the absorption band. An increase in band gap with the increase in postannealing temperature was observed due to the blue shift in absorption edge of $\mathrm{CuO}$ causing enhanced photodegradation. The catalytic properties of the $\mathrm{CuO}$ nanofibers were tested using methylene blue in aqueous medium. The influences of parameters responsible for high photodegradation were optimized and the rate of the photodegradation process was calculated using photodegradation kinetics. The reusability test was conducted to find the stability of the fabricated $\mathrm{Zn}-\mathrm{CuO}$ nanofibers.
\end{abstract}

Keywords: copper oxide; dopant; nanofiber; electrospinning; band gap; photocatalyst

\section{Introduction}

Large surface area, chemical stability and high electron mobility are notable characteristics of transition metal oxides at nanoscale. These properties are due to the quantization effect of bulk material into nanostructured compounds. Among transition metal oxide, $\mathrm{CuO}$ is a p-type semiconductor with a narrow band gap of $1.2 \mathrm{eV}$ to $1.7 \mathrm{eV}$, widely used as a source of charge carriers [1]. It exists in two forms: as cuprous oxide $\mathrm{Cu}_{2} \mathrm{O}$ and cupric oxide $\mathrm{CuO}$ with excellent properties and promising applications in the field of lithium-ion electrode materials [2], magnetic storage materials [3], gas sensing [4], photocatalysis [5] and solar cells [6]. The physical and chemical properties of nanostructured semiconductor materials are determined through their shape, size and dimensional morphology.

*E-mail: tvenkatachalam@cit.edu.in
Various strategies have been applied by researchers to optimize such structured compounds for potential applications. One of the most important factors which determines the morphology and causes changes in physical and chemical properties is the fabrication process. Doping is a tailoring method used for changing physicochemical properties of $\mathrm{CuO}$ metal oxide by dopants, such as $\mathrm{Ce}, \mathrm{Ni}$ and $\mathrm{Zn}$, etc. [7, 8]. $\mathrm{Zn}^{2+}$ is chosen as an effective dopant since it has almost the same ionic radius and ionic states as $\mathrm{Cu}\left(\mathrm{Zn}^{2+}: 0.074 \mathrm{~nm}, \mathrm{Cu}^{2+}\right.$ : $0.072 \mathrm{~nm})$. As a result, $\mathrm{Zn}$ can easily be doped into $\mathrm{CuO}$ matrix and produce effective defects in the $\mathrm{CuO}$ nanostructures [9]. Post-annealing time is a commonly used optimizing parameter which can cause a change in oxidation state of copper resulting in the change of physical and chemical properties. Xi et al. [10] observed a change in size and morphology from microsphere to nanowires with an increase in post-annealing temperature 
in synthesized $\mathrm{CuO}$ nanowires using hydrothermal method. Sahay et al. [11] observed a change in crystallite size of $\mathrm{CuO}$ nanowires with an increase in post-annealing temperature and dwelling time using sol-gel method.

Many synthesizing techniques, hydrothermal [12], electrochemical deposition [13], sol-gel technology [14] and chemical vapour deposition [15] have been used for synthesis of $\mathrm{CuO}$ nanomaterials with controlled shape and size. Electrospinning is the most commonly explored method for synthesizing 1D nanostructured materials since it is the simplest, economical and most versatile technique for synthesizing nanofibers with various compositions, uniform diameter and significant length. Electrospinning is a process in which the high voltage is applied to a polymer droplet at the syringe needle tip. Charge built up over the droplet elongates it, which results in formation of a Taylor cone as soon as the charge overcomes the precursor solution surface tension [16].

Large amount of synthetic organic dyes is used in textile, leather, cosmetics, plastics, food and pharmaceutical industries in dyeing process which consumes large amount of water in finishing process [17-23]. The wastewater containing the dyestuff is carcinogenic and mutagenic, is highly stable in light and contains bleaching agents, therefore it should be properly treated before entering into the living environment [24-32]. Among commonly used industrial dyes, methylene blue is considered as a predominant cationic dye used in major industries such as paper, textile, cotton, leather, silk, etc. These industrial effluents cause harmful effects to the plant species since they do not allow the light transmission to the root through wastewater causing disruption in the growth [3336]. Several methods have been employed for the removal of toxic dyes from wastewater. Adsorption is a widely used method but there are some disadvantages, such as production of secondary effluents and spent adsorbents [37]. Hence, an alternative to minimize the disadvantages faced in adsorption method is the dye effluent treatment which has to be both cost efficient and economical [38-40].
Photocatalysis is considered to be the most effective and economical method used for treating textile dye effluents. Transition metal oxide $\mathrm{Zn}-\mathrm{CuO}$, when used as a photocatalyst, has the ability to produce $\mathrm{OH}^{\bullet}$ radicals which play an active role in the degradation of organic dyes.

In the present paper, $\mathrm{Zn}-\mathrm{CuO}$ nanofiber was fabricated through electrospinning method using lab scale designed nanofiber generator unit. The fabricated $\mathrm{Zn}$ doped $\mathrm{CuO}$ nanofibers were characterized using spectral techniques to find out the surface/structural morphology, chemical composition and physical nature of this compound. The $\mathrm{Zn}-\mathrm{CuO}$ nanofiber were annealed at different post-annealing temperatures $400{ }^{\circ} \mathrm{C}, 500{ }^{\circ} \mathrm{C}$ and $600^{\circ} \mathrm{C}$ separately. The so prepared $\mathrm{Zn}-\mathrm{CuO}$ nanofibers were tested as a photocatalyst for the degradation of toxic organic dyes from wastewater in a photodegradation process. The process parameters were optimized and explained in detail. Langmuir-Hinshelwood (L-H) kinetics model was applied to the obtained experimental data, to find the nature, reaction rate and spontaneity of the process. In order to find the stability nature of the $\mathrm{Zn}-\mathrm{CuO}$ nanofibers, recycling experiments were carried out.

\section{Experimental}

\subsection{Preparation of $\mathrm{CuO}$ precursor solu- tion}

$2 \mathrm{~g}$ of copper acetate $\left(\mathrm{Cu}\left(\mathrm{CH}_{3} \mathrm{COO}\right)_{2} \cdot \mathrm{H}_{2} \mathrm{O}\right.$, Sigma-Aldrich), $0.1 \mathrm{~g}$ of zinc acetate $\left(\mathrm{Zn}\left(\mathrm{O}_{2} \mathrm{CCH}_{3}\right)_{2} \cdot\left(\mathrm{H}_{2} \mathrm{O}\right)_{2}\right.$, Sigma-Aldrich) and $1.2 \mathrm{~g}$ of sodium hydroxide $(\mathrm{NaOH}$, Merck) were grinded separately in a mortar with a pestle. The obtained fine powders of acetate salts and sodium hydroxide were mixed with $3.6 \mathrm{~mL}$ of polyethylene glycol (PEG 400, Sigma-Aldrich) and made into a fine paste. The paste was washed repeatedly with distilled water under magnetic stirring and finally dried in ethanol medium. The obtained pale blue colored paste was sintered at $70{ }^{\circ} \mathrm{C}$ in an oven for $2 \mathrm{~h}$ and annealed at $400{ }^{\circ} \mathrm{C}, 500^{\circ} \mathrm{C}$ and $600{ }^{\circ} \mathrm{C}$ separately for $2 \mathrm{~h}$. The annealed $\mathrm{Zn}-\mathrm{CuO}$ precursor samples were mixed separately with polyvinyl alcohol (PVA, Sigma-Aldrich) and used for the generation of $\mathrm{Zn}$ doped $\mathrm{CuO}$ nanofibers. 


\subsection{Preparation of $\mathrm{Zn}$ doped $\mathrm{CuO}$ nanofibers}

$\mathrm{Zn}$ doped $\mathrm{CuO}$ precursor was dissolved in ethanol and sonicated for $30 \mathrm{~min}$ to get a homogeneous solution. The homogeneous precursor solution was filled in a syringe (fiber producing unit) which was connected with a hypodermic needle (dia. 27) placed inside the designed nanofiber generator unit (Fig. 1).

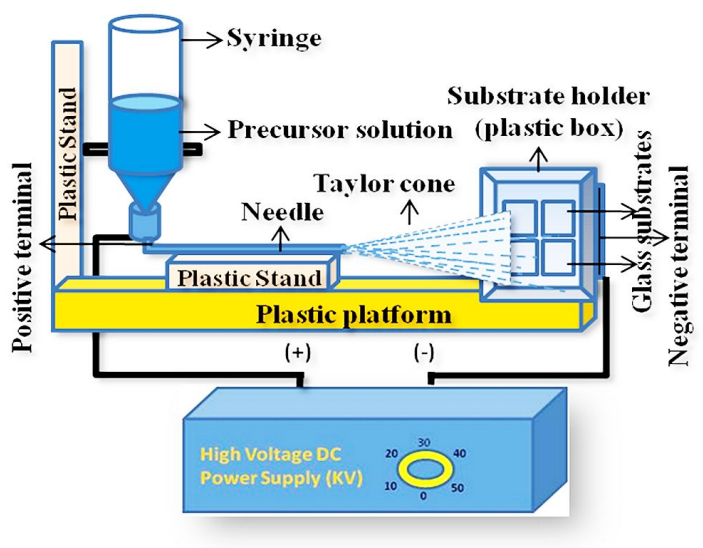

Fig. 1. General outline of designed nanofiber generator.

The designed nanofiber generating unit consists of three major sections: (i) power supply unit based on a microcontroller unit able to generate $0 \mathrm{kV}$ to $30 \mathrm{kV}$ voltage between the needle and the collecting unit; (ii) nanofiber production unit, in which the spinneret solution is fed with a syringe and made to flow through the hypodermic needle to produce droplets. The needle is connected to the positive terminal and the collecting unit is connected to the negative terminal; (iii) nanofiber collector unit with the flow rate of $0.2 \mathrm{~mL} / \mathrm{h}$ and applied field of $25 \mathrm{kV} / \mathrm{cm}$; a distance of $8 \mathrm{~cm}$ is kept between the needle tip and the collector, the droplets formed at the tip of the needle ooze out which results in tailored cones and as a result nanofibers are deposited on four glass substrate plates. The fabricated nanofibers are then collected, covered with lids and subjected to characterization.

\subsection{Characterization}

The structural and morphological characterizations of the $\mathrm{Zn}-\mathrm{CuO}$ nanofibers were carried out with X'Pert PRO, X-ray diffractometer using $\mathrm{CuK} \alpha$ radiation $(\lambda=1.5406 \AA)$. The surface morphological properties of the nanofibers were characterized using scanning electron microscope (JEOL, JSM) and energy dispersive EDX spectrometry. The optical properties of $\mathrm{Zn}-\mathrm{CuO}$ nanofibers were studied by measuring UV-reflectance spectra with UV-Vis spectrophotometer (Shimadzu UV-2100) in the range between $200 \mathrm{~nm}$ and $800 \mathrm{~nm}$. Fourier transformation analysis of $\mathrm{Zn}-\mathrm{CuO}$ nanofibers was carried out with Thermal Nicolet 6700, NEXUS. The photoluminescence studies of the prepared $\mathrm{Zn}-\mathrm{CuO}$ nanofibers were performed using a spectrometer (LABRAM 800) equipped with a $\mathrm{He}-\mathrm{Cd}$ laser excitation source. The absorbance of methylene blue dye was measured using UV spectrophotometer (Shimadzu UV-3600).

\section{Results and discussion}

\subsection{Characterization of $\mathrm{Zn}-\mathrm{CuO}$ nanofibers}

The XRD patterns of post-annealed $\mathrm{Zn}$ doped $\mathrm{CuO}$ nanofibers were recorded in the $2 \theta$ range of $10^{\circ}$ to $80^{\circ}$ and are presented in Fig. 2.

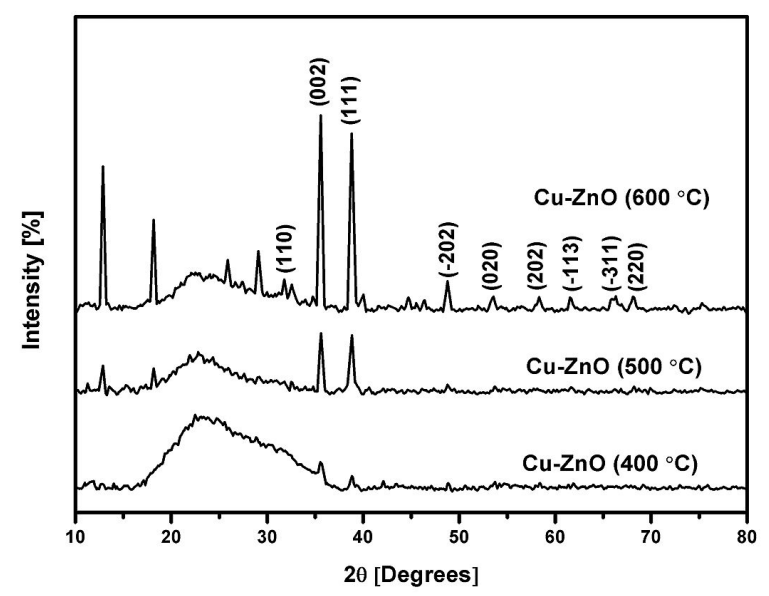

Fig. 2. XRD patterns of $\mathrm{Zn}-\mathrm{CuO}$ nanofibers postannealed at different temperatures.

The sharp peaks with high intensity show the crystalline nature of $\mathrm{Zn}-\mathrm{CuO}$ nanofibers. The peaks observed at $32.29^{\circ}\left(\begin{array}{lll}1 & 1 & 0\end{array}\right), 35.35^{\circ}\left(\begin{array}{lll}-1 & 1 & 1\end{array}\right), 38.55^{\circ}$ 
(l 111$), 48.61^{\circ}\left(\begin{array}{lll}-2 & 0 & 2\end{array}\right), 53.20^{\circ}\left(\begin{array}{lll}0 & 2 & 0\end{array}\right), 58.16^{\circ}$ (2 02$), 61.29^{\circ}(-113), 66.17^{\circ}(-311)$ and $67.77^{\circ}$ (1 113 ) correspond to the monoclinic structure of $\mathrm{Zn}$ doped $\mathrm{CuO}$ nanofibers (space group $\mathrm{C}_{2} / \mathrm{c}$ ). With an increase in the post annealing temperature, the diffraction peaks get broadened due to the reduction of crystallite size of the $\mathrm{Zn}-\mathrm{CuO}$ nanofiber. The crystallite sizes of the nanofiber were calculated using Scherrer equation:

$$
D=\frac{0.94 \lambda}{\beta \cos \theta}
$$

where $D$ is the crystallite size, $\lambda$ is the wavelength (1.546 $\AA$ for $\operatorname{Cuk} \alpha$ ), $\beta$ is the full-width at halfmaximum (FWHM) of intensity peak after subtracting the equipment broadening and $\theta$ is the diffraction angle. The relation for strain is:

$$
\varepsilon=\frac{\beta \cot \theta}{4}
$$

A graph showing crystallite size and lattice strain as a function of post-annealing temperature is shown in Fig. 3.

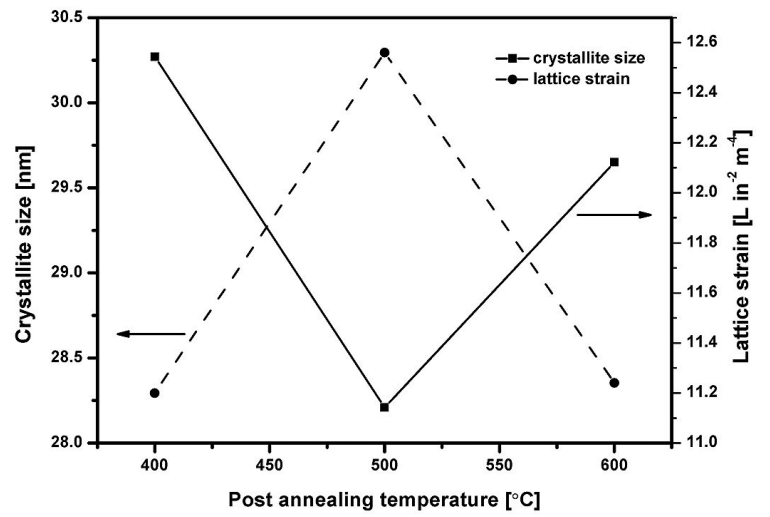

Fig. 3. Crystallite size and lattice strain as a function of post annealing temperature.

As expected, the lattice strain increases with a decrease in crystallite size of the $\mathrm{Zn}-\mathrm{CuO}$ nanofiber. Furthermore, the sharp intense peaks at $2 \theta=35.46^{\circ}, 42.12^{\circ}$ corresponding to $\mathrm{Zn}$ dopant addition grow higher with the increase in the post annealing temperature, indicating the incorporation of $\mathrm{Zn}^{2+}$ into $\mathrm{CuO}$ lattice which corresponds to the JCPDS Card No. 41-1442. Since the atomic radii of $\mathrm{Zn}^{2+}(0.074 \AA)$ and $\mathrm{Cu}^{2+}(0.073 \AA)$ are very similar, hence $\mathrm{Zn}^{2+}$ has been successfully incorporated without causing any changes to the parent $\mathrm{CuO}$ matrix. The crystallite sizes of postannealed $\mathrm{Zn}-\mathrm{CuO}$ nanofibers were calculated using Scherrer equation and are presented in Table 1, along with lattice strain and other parameters calculated from the XRD images.

The surface morphology of the post-annealed $\mathrm{Zn}-\mathrm{CuO}$ nanofibers was analyzed using SEM micrographs presented in Fig. 4. The samples of $\mathrm{Zn}-$ $\mathrm{CuO}$ nanofibers post-annealed at $400{ }^{\circ} \mathrm{C}, 500{ }^{\circ} \mathrm{C}$ and $600{ }^{\circ} \mathrm{C}$ are shown separately along with their EDX analysis results. From the SEM micrographs observations, it is clear that the $\mathrm{Zn}-\mathrm{CuO}$ nanofibers show clusters of agglomeration of particles with cylindrical shape. With an increase in temperature, agglomeration of $\mathrm{Zn}^{2+}$ over the $\mathrm{CuO}$ matrix can be observed clearly. Incorporation of $\mathrm{Zn}^{2+}$ into $\mathrm{CuO}$ matrix results in molecular structural disorder and lattice strain causing clustering of nanostructures. The EDX results show the presence of $\mathrm{Zn}^{2+}, \mathrm{Cu}^{2+}$ along with oxygen $\mathrm{O}$ suggesting the formation of mixed metal oxide formation. The presence of $\mathrm{Si}$ atom is due to the collector plate. The percentage composition of elements present in each postannealed $\mathrm{Zn}-\mathrm{CuO}$ nanofiber sample are presented in Table 2.

The FT-IR spectra of the post-annealed $\mathrm{Zn}-\mathrm{CuO}$ nanofibers are presented in Fig. 5.

From the observations, the band between $400 \mathrm{~cm}^{-1}$ to $700 \mathrm{~cm}^{-1}$ corresponds to the metal oxide bond [41]. The bands positioned at $531 \mathrm{~cm}^{-1}$ and $533 \mathrm{~cm}^{-1}$ correspond to the $\mathrm{Cu}-$ $\mathrm{O}$ stretching vibrations. The other characteristic peaks representing polycrystalline nature of $\mathrm{CuO}$ nanofibers are positioned at $487 \mathrm{~cm}^{-1}, 484 \mathrm{~cm}^{-1}$, $481 \mathrm{~cm}^{-1}$ and $483 \mathrm{~cm}^{-1}$, respectively. The broad peak at $3490 \mathrm{~cm}^{-1}$ corresponds to the $\mathrm{O}-\mathrm{H}$ stretching and bending vibration of $\mathrm{H}_{2} \mathrm{O}$ in the nanofibers. The weak bands at $2926 \mathrm{~cm}^{-1}$ and $2917 \mathrm{~cm}^{-1}$ are assigned to $\mathrm{C}-\mathrm{H}$ stretching frequency of $\mathrm{sp}^{3}$ hybridized alkyl group. The $\mathrm{CH}_{2}$ bending frequency has revealed at $1405 \mathrm{~cm}^{-1}$, $1399 \mathrm{~cm}^{-1}$ and $1401 \mathrm{~cm}^{-1}$. The weak bands observed at $1632 \mathrm{~cm}^{-1}, 1629 \mathrm{~cm}^{-1}$ and $1628 \mathrm{~cm}^{-1}$ 
Table 1. Crystallite size, lattice strain and other parameters calculated from XRD images as a function of post annealing temperature

\begin{tabular}{|c|c|c|c|c|c|c|c|c|}
\hline $\begin{array}{c}\text { Peak } \\
\text { number }\end{array}$ & $\begin{array}{c}\text { Temperature } \\
{\left[{ }^{\circ} \mathrm{C}\right]}\end{array}$ & (h k l) & $\begin{array}{c}\mathrm{d} \\
{[\AA]}\end{array}$ & $\begin{array}{c}\text { Lattice } \\
\text { parameter } \\
{[\AA]}\end{array}$ & $\begin{array}{c}\text { Crystallite } \\
\text { size D } \\
{[\mathrm{nm}]}\end{array}$ & $\begin{array}{l}\text { Stress } \\
{[\mathrm{MPa}]}\end{array}$ & Strain & $\begin{array}{c}\text { Dislocation } \\
\text { density } \\
{\left[10^{14} \times \mathrm{m}^{-2}\right]}\end{array}$ \\
\hline 1 & \multirow{4}{*}{400} & 200 & 2.317 & $\mathrm{a}=4.634$ & 27.94 & 194.34 & 12.956 & 12.807 \\
\hline 2 & & 020 & 2.588 & $b=5.177$ & 34.48 & 157.47 & 10.498 & 8.408 \\
\hline 3 & & 002 & 2.528 & $c=5.056$ & 28.40 & 191.19 & 12.74 & 12.390 \\
\hline & & \multicolumn{3}{|c|}{ Average values } & 30.27 & 181.00 & 12.064 & 11.202 \\
\hline 1 & \multirow{4}{*}{500} & 200 & 2.318 & $a=4.635$ & 27.94 & 194.34 & 12.95 & 12.807 \\
\hline 2 & & 020 & 2.220 & $\mathrm{~b}=4.440$ & 28.30 & 191.88 & 12.79 & 12.485 \\
\hline 3 & & 002 & 2.520 & $c=5.040$ & 28.40 & 191.19 & 12.74 & 12.390 \\
\hline & & \multicolumn{3}{|c|}{ Average values } & 28.21 & 192.47 & 12.826 & 12.561 \\
\hline 1 & \multirow{3}{*}{600} & 200 & 2.319 & $a=4.638$ & 29.82 & 182.11 & 12.141 & 11.245 \\
\hline 2 & & 020 & 2.252 & $b=5035$ & 28.93 & 187.66 & 12.511 & 11.942 \\
\hline \multirow[t]{2}{*}{3} & & 002 & 2.521 & $c=5.042$ & 30.80 & 176.28 & 11.75 & 10.536 \\
\hline & & \multicolumn{3}{|c|}{ Average values } & 29.85 & 182.02 & 12.134 & 11.241 \\
\hline
\end{tabular}

Table 2. EDX analysis of $\mathrm{Zn}-\mathrm{CuO}$ nanofibers post-annealed at different temperatures.

\begin{tabular}{ccccc}
\hline $\mathrm{Zn}-\mathrm{CuO}$ & $\mathrm{Zn}[w \mathrm{wt} \%]$ & $\mathrm{Cu}[w \mathrm{wt} . \%]$ & $\mathrm{Si}[w t . \%]$ & $\mathrm{O}$ [wt.\%] \\
\hline \hline $400{ }^{\circ} \mathrm{C}$ & 51.89 & 26.20 & - & 21.91 \\
$500{ }^{\circ} \mathrm{C}$ & 55.52 & 28.91 & 2.11 & 13.46 \\
$600{ }^{\circ} \mathrm{C}$ & 58.19 & 27.01 & 3.5 & 11.30 \\
\hline
\end{tabular}

correspond to the $\mathrm{C}=\mathrm{C}$ stretching frequency. These weak peaks show the presence of impurities present on the surface of the metal oxide nanofibers. The band observed between $900 \mathrm{~cm}^{-1}$ and $1500 \mathrm{~cm}^{-1}$ corresponds to the oxygen stretching and bending frequencies [42, 43]. No characteristic peaks are observed at $453 \mathrm{~cm}^{-1}$ for $\mathrm{ZnO}$ formation [44] which confirms the formation of $\mathrm{Zn}$ doped $\mathrm{CuO}$ nanofibers.

The optical properties of the $\mathrm{Zn}-\mathrm{CuO}$ nanofibers were recorded in the wavelength range of $200 \mathrm{~nm}$ to $800 \mathrm{~nm}$ (Fig. 6). Broad absorption peaks are observed around $261 \mathrm{~nm}$, $263 \mathrm{~nm}$ and $267 \mathrm{~nm}$ for the samples of $\mathrm{Zn}-\mathrm{CuO}$ post-annealed at $400{ }^{\circ} \mathrm{C}, 500{ }^{\circ} \mathrm{C}$ and $600{ }^{\circ} \mathrm{C}$, respectively and the corresponding cut-off wavelength occurs at $344 \mathrm{~nm}, 351 \mathrm{~nm}$ and $353 \mathrm{~nm}$. The weak bands for corresponding $\mathrm{Zn}-\mathrm{CuO}$ nanofibers appear at $679 \mathrm{~nm}\left(400{ }^{\circ} \mathrm{C}\right), 676 \mathrm{~nm}\left(500{ }^{\circ} \mathrm{C}\right)$ and $692 \mathrm{~nm}\left(600{ }^{\circ} \mathrm{C}\right)$, respectively. The band gaps of the post-annealed $\mathrm{Zn}-\mathrm{CuO}$ nanofibers were calculated using the equation:

$$
E=\frac{h c}{\lambda}
$$

where $\mathrm{h}$ is the Planck constant, $\mathrm{c}$ is the velocity of light and $\lambda$ is the wavelength of the UV-Vis spectrum.

The band gap energy changed due to the post annealing causing a change in the grain size of the $\mathrm{Zn}-\mathrm{CuO}$ nanofibers respectively. From the observations, the band gap of the post-annealed $\mathrm{Zn}$ $\mathrm{CuO}$ nanofibers increased with an increase in temperature. A blue shift was observed due to the quantum confinement of 1D nanostructured materials [45]. The calculated band gaps were found to be $1.86 \mathrm{eV}, 1.94 \mathrm{eV}$ and $1.98 \mathrm{eV}$ at the post annealing temperatures of $400{ }^{\circ} \mathrm{C}, 500{ }^{\circ} \mathrm{C}$ and $600{ }^{\circ} \mathrm{C}$. These results are consistent with the effective mass theory (EMA). 



Fig. 4. SEM micrographs of $\mathrm{Zn}-\mathrm{CuO}$ nanofibers along with their EDX analysis results: (a) $\mathrm{Zn}-\mathrm{CuO}$ post-annealed at $400{ }^{\circ} \mathrm{C}$; (b) $\mathrm{Zn}-\mathrm{CuO}$ postannealed at $500{ }^{\circ} \mathrm{C}$; (c): $\mathrm{Zn}-\mathrm{CuO}$ post-annealed at $600{ }^{\circ} \mathrm{C}$.

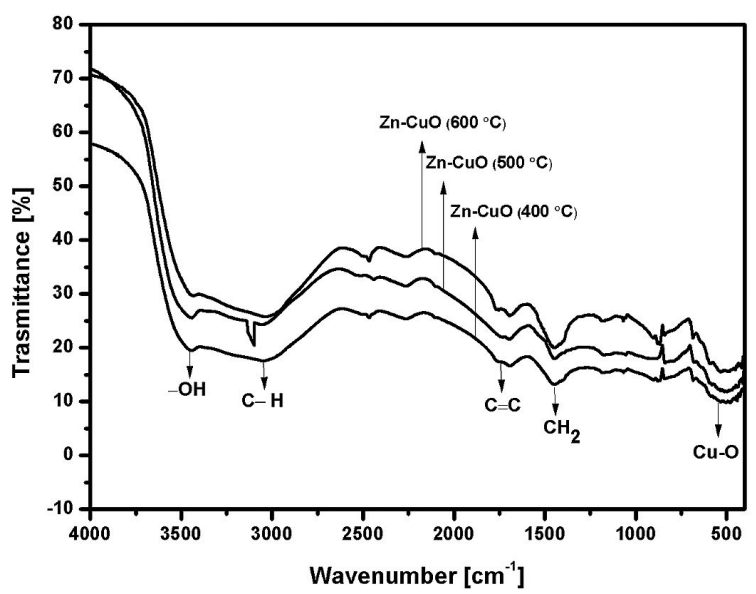

Fig. 5. FT-IR spectra of $\mathrm{Zn}-\mathrm{CuO}$ nanofibers postannealed at $400{ }^{\circ} \mathrm{C}, 500{ }^{\circ} \mathrm{C}$ and $600{ }^{\circ} \mathrm{C}$.

\subsection{Photocatalytic studies}

The photocatalytic reaction was performed using the $\mathrm{Zn}-\mathrm{CuO}$ nanofiber post-annealed at $500{ }^{\circ} \mathrm{C}$, since it shows excellent properties deduced from the characterization analysis. The collector plate

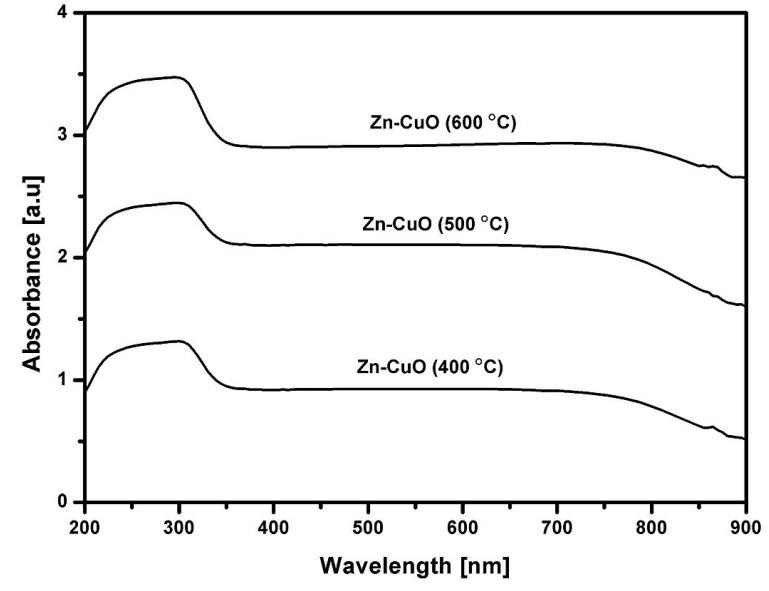

Fig. 6. UV-DRS spectra of $\mathrm{Zn}-\mathrm{CuO}$ nanofibers postannealed at $400{ }^{\circ} \mathrm{C}, 500{ }^{\circ} \mathrm{C}$ and $600{ }^{\circ} \mathrm{C}$.

containing electrospun $\mathrm{Zn}-\mathrm{CuO}$ nanofiber was suspended with the help of a holder inside the beaker containing $10 \mathrm{mg} / \mathrm{L}$ of methylene blue dye solution. The beaker was kept inside another vessel containing water flowing in and out continuously acting as a cooling chamber. The complete setup was placed upon a magnetic stirrer with a pellet placed inside the beaker containing the dye solution. A $125 \mathrm{~V}$, high pressure mercury lamp was used as a source to enhance the photodegradation of the dye. The efficiency of the photodegradation of methylene blue dye using prepared $\mathrm{Zn}-\mathrm{CuO}$ nanofiber was calculated with the absorbance measured using UV-Vis spectrophotometer (Shimadzu 3600) using the equation:

$$
\text { Process effeciency }[\%]=\frac{C-C_{o}}{C} \times 100
$$

where $\mathrm{C}$ is the initial concentration and $\mathrm{C}_{\mathrm{o}}$ is the concentration of methylene blue dye solution at time $\mathrm{t}(\mathrm{mg} / \mathrm{L})$.

\subsubsection{Process optimization}

The photocatalytic degradation of methylene blue dye was carried out at $\mathrm{pH}$ ranging from 4 to 9, with initial methylene blue dye concentration of $10 \mathrm{mg} / \mathrm{L}$ to $50 \mathrm{mg} / \mathrm{L}$ for a period of $180 \mathrm{~min}$ at $30 \mathrm{~min}$ regular time intervals. The experimental observations of optimization of $\mathrm{pH}$ and initial dye concentration are presented in Fig. 7. 


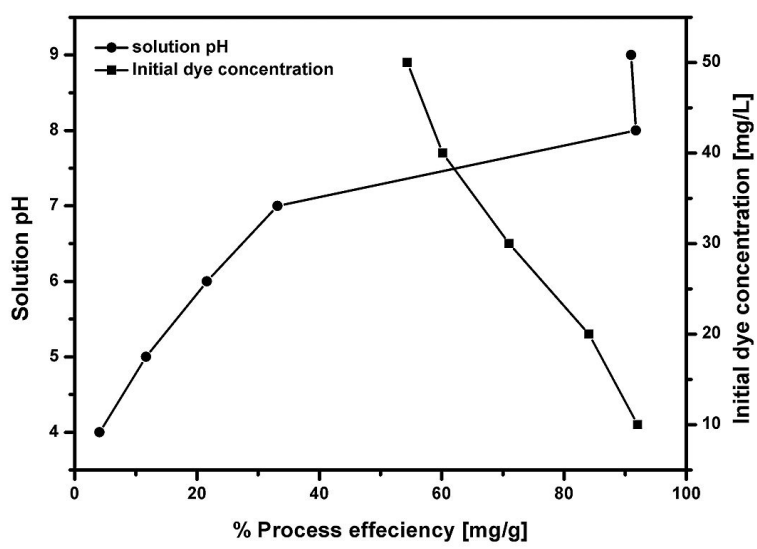

Fig. 7. Optimization of $\mathrm{pH}$ and initial dye concentration in methylene blue degradation process using $\mathrm{Zn}$ doped $\mathrm{CuO}$ nanofiber photocatalyst.

From the observations, it is clear that photodegradation efficiency is low at acidic $\mathrm{pH}$ but with gradual increase in $\mathrm{pH}$, effective decolorization of the methylene blue dye was achieved at basic $\mathrm{pH}$ of 8 . At basic $\mathrm{pH}, \mathrm{OH}^{-}$radicals shall combine with the holes present in the photocatalyst surface, generating more and more $\mathrm{OH}^{-}$radicals. Since the $\mathrm{OH}^{-}$radicals are the most dominating oxidizing species in the photodegradation process, higher degradation of MB dye takes place at the basic medium [46]. Rapid degradation takes place initially but with an increase in dye concentration, the photodegradation efficiency decreases gradually. This is mainly due to the availability of free electrons from the $\mathrm{Zn}-\mathrm{CuO}$ photocatalyst. But with an increase in dye concentration, the overcrowding of dye molecules around the photocatalyst makes the electron-hole transfer slow, resulting in slow photodegradation.

The time period required for the maximum degradation of methylene blue dye using $\mathrm{Zn}-\mathrm{CuO}$ nanofiber was analyzed and presented in Fig. 8.

The time period parameter optimization was carried out at $\mathrm{pH}=8$ in solution containing $10 \mathrm{mg} / \mathrm{L}$ of methylene blue dye. The photocatalytic experiment was conducted and solution was withdrawn at every 30 min time intervals, centrifuged (1000 rpm) and analyzed using UV-Vis spectrophotometer. A spectrum with a sharp peak

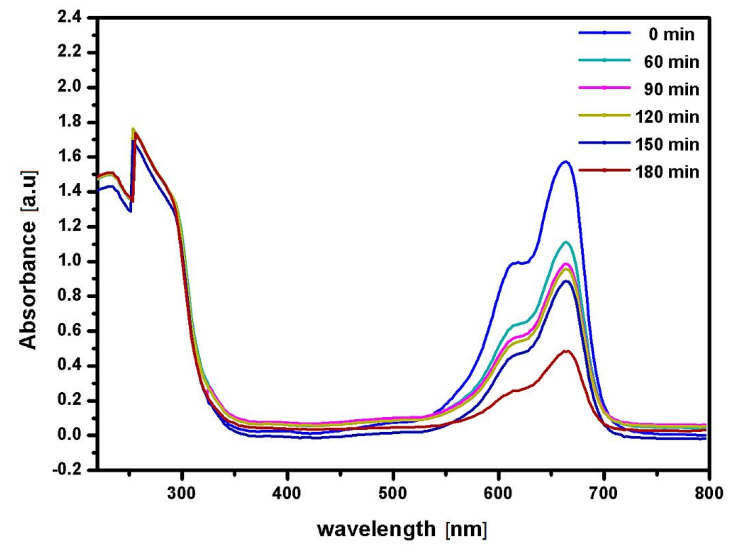

Fig. 8. Time period optimization of methylene blue degradation using $\mathrm{Zn}-\mathrm{CuO}$ nanofiber.

at a wavelength of $664 \mathrm{~nm}$ was obtained. After every time interval, the intensity of the peak diminished, depicting the degradation of methylene blue dye. After $180 \mathrm{~min}$, maximum degradation took place. The decrease in peak intensity was due to the interaction between the electrons generated by the $\mathrm{Zn}-\mathrm{CuO}$ photocatalyst and the dye molecules present in the solution. Subsequent degradation of dye molecules was caused by the photocatalyst at a particular time, when no more dye molecules were available.

\subsection{Photocatalytic kinetics}

The photocatalytic activity of $\mathrm{Zn}$ doped $\mathrm{CuO}$ nanofiber was evaluated by calculating the rate of photodegradation of methylene blue dye. The light induced photodegradation of methylene blue dye follows first order kinetic model obeying Langmuir-Hinshelwood model [47, 48]. For better understanding of the photocatalytic reaction, kinetics of methylene blue dye degradation experiments were conducted. The degradation data were analyzed using pseudo-first order kinetic model [49] expressed by the equation:

$$
-\ln \frac{C}{C_{o}}=k t
$$

where $\mathrm{C}$ and $\mathrm{C}_{\mathrm{o}}$ represent the concentration of methylene blue dye solution at time zero and $\mathrm{t}$, and $\mathrm{k}$ is the pseudo-first order rate constant. A plot of $-\ln (\mathrm{C} / \mathrm{Co})$ against time $t$ is presented in Fig. 9. 


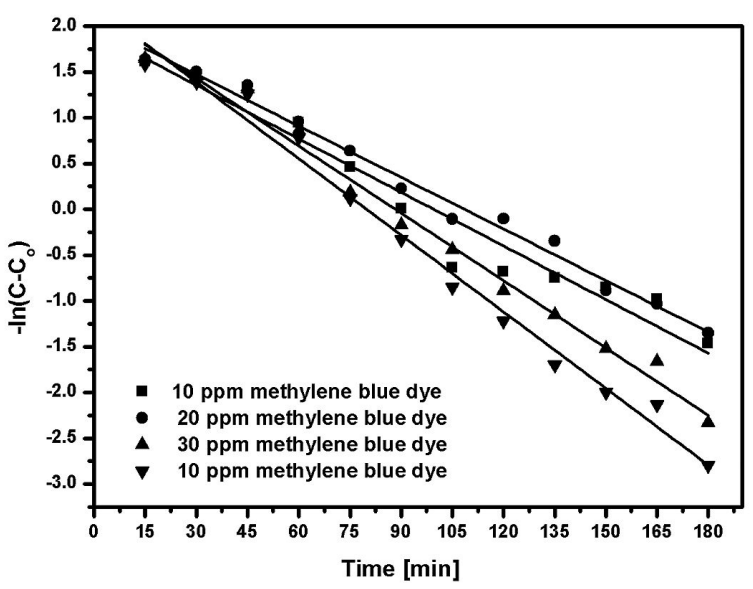

Fig. 9. Photodegradation kinetics of methylene blue dye using $\mathrm{Zn}-\mathrm{CuO}$ nanofiber photocatalyst.

The values of rate constant and correlation coefficient $\left(\mathrm{R}^{2}\right)$ were calculated and presented in Table 3.

The effect of addition of $\mathrm{Zn}$ dopant into the $\mathrm{CuO}$ matrix resulted in the production of electronhole pair and after reacting with sufficient amount of chemical elements, the hydroxyl group ions got converted into superoxy radicals $\mathrm{O}_{2}^{\bullet-}$ and hydroxyl $\mathrm{OH}^{\bullet}$ radicals which effectively supressed the recombination of electron-hole pairs. The excessive negative potential in the conduction band causes the electrons to reduce the molecular oxygen to superoxide radicals and the excessive positive potential present in the valence band causes the holes to directly react with the water to yield hydroxyl radicals or degrades the methylene blue dye directly. The hydroxide radicals have an ability to oxidize dye molecules or generate electron-hole pair [50].

\subsection{Reusability test}

The reusability test of the $\mathrm{Zn}-\mathrm{CuO}$ nanofiber was performed to assess cost-effectiveness of the photodegradation system. For each experiment, the $\mathrm{Zn}-\mathrm{CuO}$ photocatalyst was used with a freshly prepared methylene blue dye solution. The observations are presented in Fig. 10.

The $\mathrm{Zn}-\mathrm{CuO}$ nanofiber was found to be stable up to four consecutive cycles and slowly lost its properties. This was due to the limited stability and slow oxidation potential

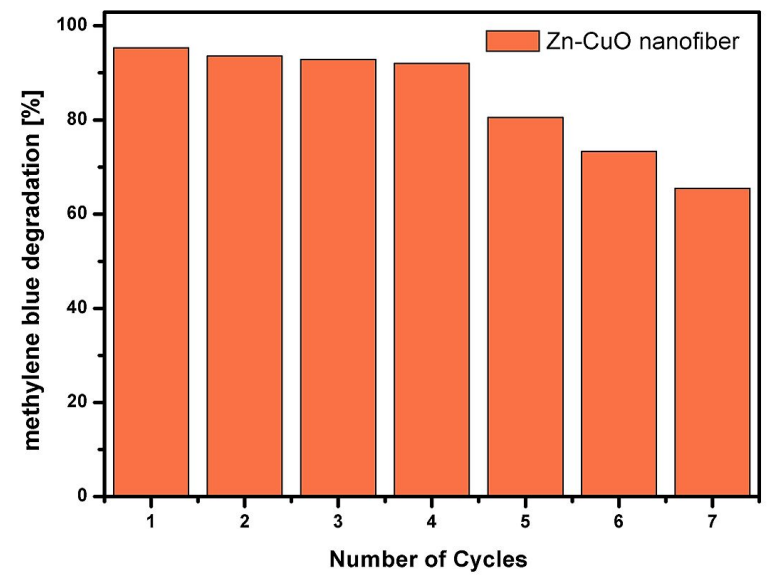

Fig. 10. Reusability studies of $\mathrm{Zn}-\mathrm{CuO}$ nanofiber photocatalyst.

of the photocatalyst employed [51]. The reusability results showed the practical applicability of the $\mathrm{Zn}-\mathrm{CuO}$ nanofiber which was found to be effective due to the molecular integrity of the co-doped sample and stability of the catalyst.

\section{Conclusions}

In summary, the $\mathrm{Zn}-\mathrm{CuO}$ precursors postannealed at different temperatures $\left(400{ }^{\circ} \mathrm{C}, 500{ }^{\circ} \mathrm{C}\right.$ and $600{ }^{\circ} \mathrm{C}$ ) were electrospun onto nanofibers using the designed nanofiber generator. The effect of post-annealing temperature on the formation of nanofibers was analyzed. It was observed that the crystallite size of the nanofiber decreased with an increase in the-post annealing temperature. From the spectral characterization results it was stated that the incorporation of $\mathrm{Zn}^{2+}$ into $\mathrm{CuO}$ matrix resulted in the formation of spherically-shaped nanostructured material of $30 \mathrm{~nm}$ average crystallite size. The optical study showed that incorporation of $\mathrm{Zn}$ into $\mathrm{CuO}$ matrix caused an increase in the band gap, whose value raised also with an increase in the post-annealing temperature. A blue shift was observed in the absorption band, enhancing photocatalytic activity. The highly ordered $\mathrm{Zn}-\mathrm{CuO}$ nanofiber was employed for the photocatalytic studies. Maximum methylene blue degradation was achieved with $10 \mathrm{ppm}$ of methylene blue solution at pH 8 in $180 \mathrm{~min}$. Reaction kinetics was employed to study the role of $\mathrm{Zn}-\mathrm{CuO}$ nanofiber 
Table 3. Kinetic parameters of $\mathrm{Zn}-\mathrm{CuO}$ nanofiber used for the photodegradation of methylene blue dye

\begin{tabular}{cccc}
\hline Sample & $\begin{array}{c}\text { Methylene blue concentration } \\
{[\mathrm{ppm}]}\end{array}$ & $\mathrm{K}\left[\mathrm{min}^{-1}\right]$ & $\mathrm{R}^{2}$ \\
\hline \hline & 10 & 0.3319 & 0.9905 \\
$\mathrm{Zn}-\mathrm{CuO}\left(500{ }^{\circ} \mathrm{C}\right)$ & 20 & 0.2987 & 0.9635 \\
& 30 & 0.3176 & 0.9918 \\
& 40 & 0.3028 & 0.9785 \\
\hline
\end{tabular}

as a photocatalyst for effective photodegradation process. Reusability test was performed and stability up to four consecutive cycles was found. To sum up, we have fabricated $\mathrm{Zn}-\mathrm{CuO}$ nanofibers which can be effectively used in environmental applications.

\section{Acknowledgements}

The authors would like to express their sincere thanks to Dr. S.R.K. Prasad (Correspondent, CIT), Dr. R. Prabhakar (Secretary, CIT), Dr. V. Selladurai (Principal, CIT), Mr. S. Rajiv Rangasamy (Director, CIT), Correspondent of KCT, Secretary of KCT and Principal of KCT for their help and encouragement during work.

\section{References}

[1] Kaura M., Muthea K.P., Despandeb S.K., Choudhury C.S., Singhd J.B., Vermae N., GuPTAA S.K., YAKhмiA J.V., J. Cryst. Growth, 289 (2006), 670.

[2] GaO X.P., Bao J.L., Pan G.L., Zhu H.Y., Huang P.X., Wu F., Song D.Y., J. Phys. Chem. B, 108 (2004), 5547.

[3] Wang S.Q., Zhang J.Y., Chen C.H., Scripta Mater., 57 (2007), 337.

[4] Li J.Y., XiOng S.L., Xi B.J., LI X.G., QIAN Y.T., Cryst. Growth Des., 9 (2009), 4108.

[5] Vaseem M., Umar A., Hahn Y.B., Kim D.H., Lee K.S., JANG J.S., LeE J.S., Catal. Commun., 10 (2008), 11.

[6] Xu Y., Chen D., Jiao X., J. Phys. Chem. B, 109 (2005), 13561.

[7] Al-Amri S., Ansari M.S., Rafique S., Aldhahri M., Rahimuddin S., Azam A., Memic A., Curr. Nanosci., 11 (2015), 191.

[8] JAN T., IQBAL J., MANSOOR Q., ISMAIL M., NAQVI S.H., Gul A., Naqvi S.F.H., AbBas F., J. Phys. $D$ Appl. Phys., 47 (2014), 355301.

[9] IQbal J., Jan T., Ul-Hassan S., Ahmed I., ManSOOR Q., Ali M.U., ABbas F., Ismail M., AIP Adv., 5 (2015), 127112.

[10] XI Y., Hu C., Gao P., Yang R., He X., Wang X., WAN B., Mater. Sci. Eng. B-Adv., 166 (2009), 113.

[11] Sahay R., Sundaramurthy J., Kumar P.S., ThaVASi V., MHAisalkar S.G., RAMAKRISHNA S., J. Solid State Chem., 186 (2012), 261.
[12] Dar M.A., Kim Y.S., Kim W.B., Sohn J.M., ShIN H.S., Appl. Surf. Sci., 254 (2008), 7477.

[13] Chen L., Shet S., TANG H.W., WANG H.L., Deutsch T., Yan Y.F., Turner J., Aljassim M., J. Mater. Chem., 20 (2010), 6962.

[14] Ray S.C., Sol. Energ. Mat. Sol. C., 68 (2001) 307.

[15] Maruyama T., Sol. Energ. Mat. Sol. C., 56 (1998) 85.

[16] Reneker D.H., YARIN A.L., Polymer, 49 (2008) 2387.

[17] Kumar P.S., Abhinaya R.V., Arthi V., Gayathrilashmi K., Priyadharshini M., Sivanesan S., Environ. Eng. Manag. J., 13 (2014) 545.

[18] Vidhyadevi T., Murugesan A., Kalaivani S.S., PrEmKumar M.P., Kumar V.V., RAVIKUMAR L.R., Sivanesan S., Desal. Water Treat., 52 (2014) 19.

[19] Vidhyadevi T., Murugesan A., Kalaivani S.S., PremkUmar M.P., RAViKumar L., Sivanesan S., Korean J. Chem. Eng., 32 (2015) 650.

[20] Senthamarai C., Kumar P.S., PriyadHARSHINI M., ViJaYAlaKShMi P., KUMAR V.V., BASKARALINGAM P., ThiRUVEngadaraVi K.V., Sivanesan S., Environ. Prog. Sustain. Energ., 32 (2013) 624.

[21] Kumar P.S., Ramalingam S., SAThyaselvaBala V., Kirupha S.D., Sivanesan S., Desalination, 266 (2011) 63.

[22] Kumar P.S., Sathyaselvabala V., RamakrishNAN K., Vijayalakshmi P., Sivanesan S., Russ. Chem. Bull., 59 (2010) 1859.

[23] Kumar P.S., Ramalingam S., Kirupha S.D., MURUGesan A., Vidhyadevi T., Sivanesan S., Chem. Eng. J., 167 (2011) 122.

[24] Kumar P.S., Sathyaselvabala V., Kirupha S.D., ViJayalakshmi P., Sivanesan S., Environ. Eng. Manag. J., 10 (2011) 285.

[25] Kumar P.S., Ramalingam S., Abhinaya V., THIRUVENGADARAVI K.V., BASKARALINGAM P., Sivanesan S., Sep. Sci. Technol., 46 (2011) 2436.

[26] Kumar P.S., Ramalingam S., Abhinaya V., Kirupha S.D., VidhyadeVi T., Sivanesan S., Can. J. Chem. Eng., 90 (2012) 973.

[27] Kumar P.S., Ramalingam S., Abhinaya R.V., Kirupha S.D., Murugesan A., Sivanesan S., Clean, 40 (2012) 188.

[28] Kumar P.S., Ramalingam S., SathyaselvaBala V., Kirupha S.D., Murugesan A., SivaneSAN S., Korean J. Chem. Eng., 29 (2012) 756. 
[29] Rajkumar P., Kumar P.S., Kirupha S.D., Vidhyadevi T., Nandagopal J., Sivanesan S., Environ. Prog. Sustain. Energ., 32 (2013) 307.

[30] Kumar P.S., Senthamarai C., Durgadevi A., Environ. Prog. Sustain. Energ., 33 (2014) 28.

[31] Kumar P.S., Senthamarai C., Sai Deepthi A.S.L., Bharani R., Can. J. Chem. Eng., 91 (2013) 1950.

[32] Saravanan A., Kumar P.S., Yashwanthraj M., Desal. Water Treat., 68 (2017) 245.

[33] KumaR P.S., Varjani S.J., Suganya S., Bioresour. Technol., 250 (2018) 716.

[34] SaraVANAN A., KUMAR P.S., RAJAN P.S.S., Abishek S., Abhishek D., Korean J. Chem. Eng., 33 (2016) 2716.

[35] Carolin C.F., Saravanan A., Kumar P.S., RAJAN P.S., KUMAR V.V., IET Nanobiotechnol., 11 (2017) 433.

[36] Carolin C.F., Kumar P.S., Saravanan A., Joshiba G.J., Naushad M., J. Environ. Chem. Eng., 5 (2017) 2782.

[37] Xu L., Zhou Y., Wu Z., Zheng G., He J., Zhou Y., J. Phys. Chem. Solids, 106 (2017), 29.

[38] Gunasundari E., Kumar P.S., J. Ind. Eng. Chem., 56 (2017) 129.

[39] Saravanan A., Kumar P.S., Renita A.A., J. Clean. Prod., 172 (2018) 92.

[40] Kumar P.S., PalaniyapPan M., PriYadHARShini M., Vignesh A.M., ThANJIAPPAN A., FERnANdo P.S.A., AhMED R.T., SRINATHA R., Environ. Prog. Sustain. Energ., 33 (2014) 87.
[41] Saravanan R., Karthikeyan S., Gupta V.K., Sekaran G., Narayanan V., Stephen A., Mater. Sci. Eng. C, 33 (2013), 91.

[42] ZhU J.W., Li D., YAng X.J., LU L.D., Wang X., Mater. Lett., 58 (2004), 3324.

[43] Hammad T.M., SAlem J.K., Harrison R.G., Rev. Adv. Mater. Sci., 22 (2009), 74.

[44] Oda A.M., Ali H.H., Lafta A.J., Esmael H.A., Jameel A.A., Mohammed A.M., Mubarak I.J., Int. J. Chem., 7 (2015), 39.

[45] Sahay R., Sundaramurthy J., Kumar P.S., ThaVAsi V., Mhaisalkar S.G., Ramakrishna S., J. Solid State Chem., 186 (2012) 261.

[46] Pitchaimuthu S., Rajalakshmi S., Kannan N., Velus amy P., Desalin. Water Treat., 52 (2014), 3392.

[47] Bayati M.R., Golestani-Fard F., Moshfegh A.Z., Appl. Surf. Sci., 256 (2010) 4253.

[48] Bechambi O., Jlaiel L., NajJar W., Sayadi S., Mater. Chem. Phys., 173 (2016) 95.

[49] Naseri A., Samadi M., Mahmoodi N.M., PourJavadi A., Mehdipour H., Moshfegh A.Z., $J$. Phys. Chem. C, 121 (2017) 3327.

[50] Eswaran K., Sivaraman S., Kavitha B., Prema E.M., Rajarajan M., Park S., Appl. Surf. Sci., 433 (2018) 216.

[51] Arunadevi R., Kavitha B., Rajarajan M., SugAnthi A., JEYAMURUgan A., Surf. Interface, 10 (2018) 32 .

Received 2018-03-13 Accepted 2018-04-06 